\title{
Fungal Assessment of Indoor Air Quality in Wards and Operating Theatres in an Organ Transplantation Hospital
}

\author{
Seyed Ali Sajjadi ${ }^{1}$, Damon Ketabi ${ }^{2}$ and Fatemeh Joulaei ${ }^{3,{ }^{*}}$ \\ ${ }^{1}$ Department of Environmental Health Engineering, School of Health and Social Determinants of Health Research Center, Gonabad University of Medical Sciences, Gonabad, \\ Iran \\ ${ }^{2}$ Department of Occupational and Environmental Health Engineering, School of Health, Mashhad University of Medical Sciences, Mashhad, Iran \\ ${ }^{3}$ Student Research Committee, Department of Environmental Health Engineering, Gonabad University of Medical Sciences, Gonabad, Iran \\ "Corresponding author: Fatemeh Joulaei, Student Research Committee, Department of Environmental Health Engineering, Gonabad University of Medical Sciences, Gonabad, \\ Iran. Tel: +98-9153598294, Fax: +98-5138522775, E-mail: joulaeif1@mums.ac.ir
}

Received 2017 August 14; Revised 2017 October 21; Accepted 2017 December 09.

\begin{abstract}
Background: Fungi are ubiquitous in indoor environments and are responsible for a wide range of infections in immunocompromised patients.

Objectives: This study aimed to determine the type and amount of fungal contamination in an organ transplantation hospital in Mashhad.

Methods: In this cross-sectional study, 96 samples were taken from three operating theatres, hemodialysis wards for women and men, kidney and liver transplant wards, and intensive care unit (ICU) of an organ transplant hospital of Mashhad University of Medical Sciences. Air samples were taken according to the NIOSH standard instructions and Anderson procedure with a flow rate of 28.3 L per two minutes on sabarose dextrose agar media.

Results: Among the five wards, liver transplantation was the least contaminated of fungal concentration in indoor air $(5.53 \pm 4.08$ $\left.\mathrm{CFU} / \mathrm{m}^{3}\right)$. Indoor fungal were observed, women's hemodialysis $\left(9.01 \pm 5.57 \mathrm{CFU} / \mathrm{m}^{3}\right)$, kidney transplantation $\left(9.70 \pm 5.99 \mathrm{CFU} / \mathrm{m}^{3}\right)$, $\operatorname{ICU}\left(11.09 \pm 4.12 \mathrm{CFU} / \mathrm{m}^{3}\right)$, and men's hemodialysis $\left(11.78 \pm 8.31 \mathrm{CFU} / \mathrm{m}^{3}\right)$, respectively. The most important fungal contaminations in operating theatres respectively was related to Aspergillus and Penicillium.

Conclusions: The mean of fungal contamination in operating theatres and wards was compared with the European union good manufacturing practices guideline (EU GMP). Concentration of fungal in the hospital was in class B (clean state). However, due to the high sensitivity of transplantation recipients and immunocompromised patients to nosocomial fungal infections, the periodic surveys of the hospitals, environmental controls, and using an efficient ventilation system are necessary.
\end{abstract}

Keywords: Aspergillus, Organ Transplantation, Nosocomial Infections, Bioaerosol

\section{Background}

In the clinical management of organ transplant recipients, infectious diseases continue to be a major cause of morbidity and mortality. Every year about 1.7 million cases of nosocomial infections have been reported all around the world (1). In the past, pathogenic species have been limited in extent; however, recently, the number of pathogenic and opportunistic species is considerably increased (2). Studies have shown that there is a significant relationship between hospital infections and airborne bioaerosols (3). Fungi are present in indoor environments and play important roles in human diseases. These infections are increasing in immunosuppressed patients such as patients undergoing hematopoietic stem cell transplantation, chemotherapy for leukaemia, or AIDS
(4). Aspergillus is a common fungus in invasive infections, however, other fungi are appearing as important pathogens in immunosuppressed patients (5). Most invasive infections are acquired from indoor air. For reducing concentrations of airborne fungal, it is necessary to control measures in clinical environments $(6,7)$. Opportunistic fungal infections are the main reason of death among transplant patients and the risk of nosocomial fungal infections after transplantation may increase $(7,8)$. Reduction in the patient's defensive ability due to organ transplantation may lead to the uncontrolled multiplication of fungi and consequent onset of infection $(9,10)$. Also, we cannot completely eliminate fungi from indoor clinical environments. Fungi exposure in clinical units is unavoidable, however, for control measures, the air filtration systems can be used (11). The quality of the air in an organ 
transplant hospital is a significant role to control infections. One of the most important steps to reduce hospital infection is regular fungal monitoring (12). The present study is the first research about fungal contaminations in an organ transplant hospital in Iran. The results of this study can be used to describe the state of fungal contamination in operating theatres and wards of the hospital. Using an efficient ventilation system, reviewing the disinfection procedure, and controlling nosocomial infections are effective in decreasing fungal contamination.

\section{Methods}

The study was carried out in the organ transplantation hospital of Mashhad University of Medical Sciences, during spring, 2017. In this study, 96 samples were taken from three operating theatres and five wards; hemodialysis for women and men, kidney and liver transplant, and ICU. Air samples were collected from the operating theatres and wards once a week within three months.

In all three operating theaters there were ultraviolet lamps, while there was no ultraviolet (UV) lamp in any ward of this hospital.

According to the importance of controlling the disinfection efficiency and performance of ultraviolet lamps in operating theatres, sampling was conducted before and after disinfection and using UV radiation.

The sampling was done by an activate air sampling method based on the national institute for NIOSH-0800 instruction, by using a Quick Take SKC sampling pump and an Andersen bio-sampler, with a flow of $28.3 \mathrm{~L}$ per 2 minutes (13). In order to avoid any interference of germs or other contaminations, bio-sampler was sterilized before sampling by using disposable sterile gas and 70\% ethanol based on device catalog, and then placed under a UV lamp for 20 minutes. After sterilization, to prevent contamination until reaching to the sampling location, bio-sampler was placed in a sterilized cold box and the box was opened in the sampling location. During sampling a 90-mm plate containing medium was placed inside the bio-sampler. The sampling circuit was established at a distance of 120 $-150 \mathrm{~cm}$ from the patient's respiratory tract and any other obstacle and $100-150 \mathrm{~cm}$ from the floor $(10,14)$.

In this study, plates containing Saboro dextrose medium and chloramphenicol (SC) antibiotic were used for sampling. Sample plates were transported to the laboratory by cold boxes and incubated at $32^{\circ} \mathrm{C}$ for $7-10$ days. For early differential diagnosis of fungal genera, macroscopic examination (colonies morphology, color, texture, shape and colony apparent diameter) and microscopic mycology tests (presence of mycelium, presence of specific productive structures, shape and Conidia structure) was used (15). Due to the need for more accurate diagnosis of fungal agents, the slide culture method was also used.

Sampling was done in standard temperature and air pressure conditions, therefore, according to the volume of sampled air and the number of cultured colonies, fungal density of the indoor air of different parts of hospital in a cubic meter of air was calculated and reported by colony forming unite (CFU/ $\left.\mathrm{m}^{3}\right)$.

Due to the high sensitivity of transplantation recipients and immunocompromised patients to nosocomial fungal infections, comparison of the concentration of air fungal contamination in the hospital was necessary. The results of the present study were compared with guideline values. Good Manufacturing Practices (GMP) is a guideline of air cleaning requirements for medical device manufacturing. It recommends a total aerobic count limit of $<1$ $\mathrm{CFU} / \mathrm{m}^{3}$ in class A rooms (very clean), $<10 \mathrm{CFU} / \mathrm{m}^{3}$ in class B rooms (clean), $<100 \mathrm{CFU} / \mathrm{m}^{3}$ in class $\mathrm{C}$ rooms (medium) and $200 \mathrm{CFU} / \mathrm{m}^{3}$ in class D rooms (contaminated) (16).

The data was analyzed by the SPSS software and Chisquare test such as simple mean value, percentage, and test of significance.

\section{Results}

In this study, 8 species of fungi were detected including Aspergillus spp., Penicillium spp., Ulocladium spp., Cladosporium spp., Mucor spp., Paecilomyces spp., Hyaline filamentous fungi, and Black filamentous fungi. The average concentration of fungi in operating theatres prior to disinfection was $7.37 \pm 2.68 \mathrm{CFU} / \mathrm{m}^{3}$ and after disinfection has decreased to $3.82 \pm 2.30 \mathrm{CFU} / \mathrm{m}^{3}$ that this rate of decline was statistically significant $(\mathrm{P} \leq 0.001)$. According to the EU GMP, the average concentration of fungi in all the operating theatres were $<10 \mathrm{CFU} / \mathrm{m}^{3}$ in class $\mathrm{B}$ (clean state), (Table 1).

\begin{tabular}{|c|c|c|c|}
\hline \multirow[t]{2}{*}{ Place of Sampling } & \multicolumn{2}{|c|}{ Disinfection } & \multirow[t]{2}{*}{ P Value } \\
\hline & Before & After & \\
\hline Operating theatre 1 & $8.30 \pm 0.00$ & $4.28 \pm 2.76$ & 0.025 \\
\hline Operating theatre 2 & $5.53 \pm 4.28$ & $4.28 \pm 1.76$ & 0.063 \\
\hline Operating theatre 3 & $8.30 \pm 0.00$ & $3.38 \pm 1.38$ & 0.004 \\
\hline Total & $7.37 \pm 2.68$ & $3.82 \pm 2.30$ & 0.001 \\
\hline
\end{tabular}

${ }^{\mathrm{a}}$ Values are expressed as mean $\pm \mathrm{SD}$.

Figure 1 shows the airborne Aspergillus and Penicillium contamination in operating theatres depending on the type of fungus, before and after using UV radiation. 
The results show that the most important fungal contaminations in operating theatres respectively was related to Aspergillus and Penicillium, which decreased significantly after disinfection. In addition, according to the results, disinfection was more effective on Aspergillus than the Penicillium.

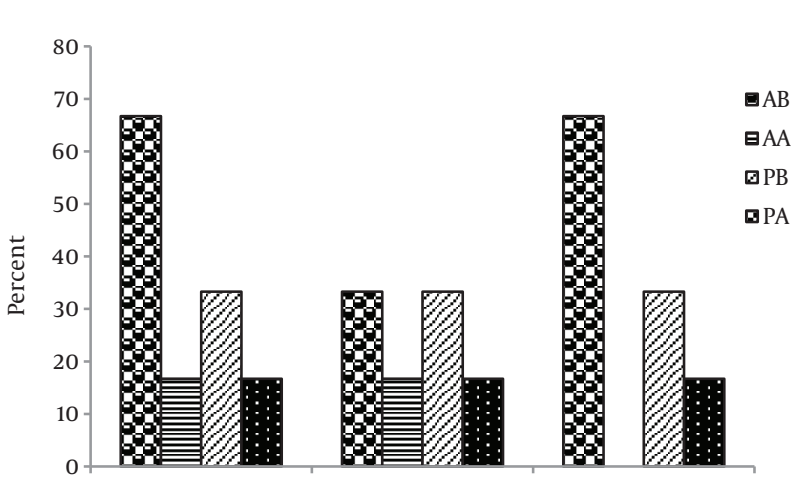

Operating Theatre 1 Operating Theatre 2 Operating Theatre 3

Figure 1. Aspergillus and Penicillium contamination in operating theatres. AB, percent Aspergillus Before using UV radiation; AA, percent Aspergillus After using UV radiation; PB, percent Penicillium Before using UV radiation, PA, percent Penicillium After using UV radiation.

The highest fungal contamination in hospital wards was related to the hemodialysis ward for men with an average of $11.78 \pm 8.31 \mathrm{CFU} / \mathrm{m}^{3}$ and the less contaminated wards were kidney transplantation, women's hemodialysis, ICU, and liver transplantation wards, respectively. The most important fungal species in hospital wards was Aspergillus, that its contamination in the men's hemodialysis, ICU, women's hemodialysis, liver transplantation and kidney transplantation wards was 58.3, 50, 33.3, 33.3, and 16.7 percent, respectively.

With the exception of the Men's Hemodialysis ward and the ICU, the mean of fungi in all the wards were in $<10$ $\mathrm{CFU} / \mathrm{m}^{3}$ in class $\mathrm{B}$ (clean state), (Table 2 ).

\section{Discussion}

Fungal concentration in all three operating theaters in after disinfection and using UV radiation was significantly lower $(\mathrm{P} \leq 0.001)$ than before using UV radiation. Concentration of fungal in the sampling operating theaters was $<10 \mathrm{CFU} / \mathrm{m}^{3}$ and indicating a clean state of indoor air (Table 1). The minimum concentration of fungal $\left(5.53 \pm 4.08 \mathrm{CFU} / \mathrm{m}^{3}\right)$ was found in liver transplantation and the maximum concentration $\left(11.78 \pm 8.31 \mathrm{CFU} / \mathrm{m}^{3}\right)$ was found in men's hemodialysis. With the exception of men's hemodialysis and the ICU, the concentration of fungal in the sampling wards was $<10 \mathrm{CFU} / \mathrm{m}^{3}$, indicating a clean state of indoor air while the men's hemodialysis and the ICU represented a middle contamination state for indoor air, as shown in Table 2. Studies suggested that levels be sustained under $10 \mathrm{CFU} / \mathrm{m}^{3}$ during surgery, which can be expected by decreasing it to $1 \mathrm{CFU} / \mathrm{m}^{3}(17,18)$. Several studies around the world have evaluated indoor air quality in clinical facilities. Values of fungal airborne in clinical wards without high efficiency particulate air (HEPA) filters are commonly between 50 and $500 \mathrm{CFU} / \mathrm{m}^{3}$ (19). In clinical wards with air filtration, airborne fungal values are $<0$ $50 \mathrm{CFU} / \mathrm{m}^{3}$ (20-23). In the present study the concentration of total fungal was lower than the reported by Chuaybamroong et al., (24) (67 CFU/m $\left.\mathrm{m}^{3}\right)$, Huang et al., (25) (12 CFU $/ \mathrm{m}^{3}$ and $59 \mathrm{CFU} / \mathrm{m}^{3}$ in ICU I and ICU II, during sampling consistency study), and Fumaglli et al., (26) (250 -300 CFU/m³ during restrictive visiting periods).

Nowadays, all efforts have been paid on designing effective programs and strategies to prevent nosocomial infections, especially infections caused by Aspergillus species in individuals who have been a candidate for an organ transplant, particularly bone marrow transplantation (27). In this study, the most important fungal contaminations in operating theatres, respectively, was related to Aspergillus and Penicillium.

In the study of Ekhaise and et al., in Nigeria, the average concentration of fungi in the air of the hospital was reported 10 to $53 \mathrm{CFU} / \mathrm{m}^{3}$ and the most species of fungi were Penicillium and Aspergillus (28). This study and another study conducted in the city of Damghan by Dehdashti (29) as well as a study conducted by Choobineh and et al., (30) were completely in accordance with the results of the current study.

Aspergillus species are a common cause of invasive fungal infections that are unable to make important invasive fungal infections in recipients. A total of $36 \%$ of nosocomial pneumonia is caused by Aspergillus species and the mortality rate of Aspergillus pneumonia has been 95\% (15). However, several studies in different cities of Iran and other countries showed that diversity of fungi in different wards have great extents. For example, in the study of Nourian and et al., the main airborne fungal contamination in different wards was related to Aspergillus, Alternaria, Penicillium, Fusarium, Cladosporium, Rhizopus, and Phoma (31), where the results of this study, in terms of the diversity of fungi, is very similar to the present study.

Awosika, in his study, reported that the most common fungi found in hospital wards were Aspergillus flavus, Penicillium, Fusarium, Candida albicans, and Alternaria (17). Despite the fact that the current study was conducted in a different geographical area, fungal diversity was almost similar to Awosika's results. In several studies conducted on samples of immunosuppression patients' bronchial in 


\begin{tabular}{|c|c|c|c|}
\hline Hospital Wards & Fungi Concentration, $\mathrm{CFU} / \mathrm{m}^{3}$, Mean $\pm \mathrm{SD}$ & Fungi Type & Frequency, \% \\
\hline \multirow{3}{*}{ Liver Transplantation } & \multirow{3}{*}{$5.53 \pm 4.08$} & Hyaline filamentous fungi & 56 \\
\hline & & Aspergillus spp. & 33.3 \\
\hline & & Penicillium spp. & 8.3 \\
\hline \multirow{4}{*}{ Women's Hemodialysis } & \multirow{4}{*}{$9.01 \pm 5.57$} & Hyaline filamentous fungi & 40.6 \\
\hline & & Aspergillus spp. & 33.3 \\
\hline & & Penicillium spp. & 25 \\
\hline & & Cladosporium spp. & 1 \\
\hline \multirow{4}{*}{ Kidney Transplantation } & \multirow{4}{*}{$9.70 \pm 5.99$} & Penicillium spp. & 41.7 \\
\hline & & Black filamentous fungi & 40.4 \\
\hline & & Aspergillus spp. & 16.7 \\
\hline & & Ulocladium spp. & 1.2 \\
\hline \multirow{5}{*}{ ICU } & \multirow{5}{*}{$11.09 \pm 4.12$} & Aspergillus spp. & 50 \\
\hline & & Penicillium spp. & 25 \\
\hline & & Mucor spp. & 8.3 \\
\hline & & Rhizopus spp. & 8.3 \\
\hline & & Hyaline filamentous fungi & 8.3 \\
\hline \multirow{3}{*}{ Men's Hemodialysis } & \multirow{3}{*}{$11.78 \pm 8.31$} & Aspergillus spp. & 58.3 \\
\hline & & Penicillium spp. & 25 \\
\hline & & Black filamentous fungi & 16 \\
\hline
\end{tabular}

different wards, various species of Aspergillus and Penicillium were identified $(32,33)$. Due to the similarity of the fungi obtained from the respiratory system of patients with fungal agents suspended in the air of the most units of hospitals, there can be a direct relationship between the fungal agents and fungal infections during the course of hospitalization in these wards.

In a study that was conducted by Hoseinzadeh et al., in Fatemie Hospital, the highest and lowest concentration of bioaerosols, respectively, was obtained in the maternity ward $1\left(54.4 \mathrm{CFU} / \mathrm{m}^{3}\right)$ and operating theatre $\left(13.3 \mathrm{CFU} / \mathrm{m}^{3}\right)$. The most common fungi identified in the hospital air were Penicillium (32.06\%), Cladosporium (20.5\%), Aspergillus fumigatus (14.61\%), and Aspergillus niger (7.43\%), respectively (34).

\subsection{Conclusions}

Based on the results of this study, the most common fungal agent in the air of operating theatres and hospital wards was Aspergillus. Aspergillus is the most frequent cause for nosocomial infections in immunocompromised patients. Due to the high sensitivity of recipients and their immunosuppression, periodic reviews of the fungal contamination, environmental controls, and using an efficient ventilation system in this hospital is necessary. Therefore, in order to reduce the number of fungal bioaerosols and improve air quality in the hospital wards, it is recommended that measures such as switching high efficiency particulate air filters, avoid opening windows for natural ventilation, regular disinfection, and also control and replacement of UV lamps and ensuring the proper functioning of them should be done. Sodium hypochlorite is usually used in the hospital and other health care settings. Other chemical compounds presenting can be used as disinfectants against fungal and their spores.

\section{Acknowledgments}

We would like to thank the staff of the operating theatre and hemodialysis, liver transplantation, kidney transplantation, and ICU wards of hospital organ transplantation in Mashhad University of Medical Sciences (MUMS), for their help. 


\section{Footnotes}

Authors' Contribution: The overall implementation of this study, including the research design, data extraction, and analysis, report writing, and manuscript preparation were the results of joint efforts by multiple individuals who are listed as co-authors of the paper.

Conflict of Interest: The authors have no conflict of interest to declare.

Funding/Support: This study was financially supported by the deputy of research, GUMS, Gonabad, Iran (grant no. 94.18).

\section{References}

1. Curtis LT. Prevention of hospital-acquired infections: review of nonpharmacological interventions. J Hosp Infect. 2008;69(3):204-19. doi: 10.1016/j.jhin.2008.03.018. [PubMed: 18513830].

2. Jiang W, Wu N, Wang X, ChiY, ZhangY, Qiu X, et al. Dysbiosis gut microbiota associated with inflammation and impaired mucosal immune function in intestine of humans with non-alcoholic fatty liver disease. Sci Rep. 2015;5:8096. doi: 10.1038/srep08096. [PubMed: 25644696]. [PubMed Central: PMC4314632].

3. Lim T, Cho J, Kim BS. The predictions of infection risk of indoor airborne transmission of diseases in high-rise hospitals: Tracer gas simulation. Energy Build. 2010;42(8):1172-81. doi: 10.1016/j.enbuild.2010.02.008.

4. Lal H, Ghosh B, Srivastava A, Srivastava A. Identification and characterization of size-segregated bioaerosols at different sites in Delhi. Aerosol Air Qual Res. 2017;17(6):1570-81. doi: 10.4209/aaqr.2015.05.0331.

5. Knibbs LD, Morawska L, Bell SC, Grzybowski P. Room ventilation and the risk of airborne infection transmission in 3 health care settings within a large teaching hospital. Am J Infect Control. 2011;39(10):86672. doi: 10.1016/j.ajic.2011.02.014. [PubMed: 21658810].

6. Perdelli F, Cristina ML, Sartini M, Spagnolo AM, Dallera M, Ottria G, et al. Fungal contamination in hospital environments. Infect Control Hosp Epidemiol. 2006;27(1):44-7. doi: 10.1086/499149. [PubMed: 16418986].

7. Pfaller MA, Diekema DJ. Epidemiology of invasive mycoses in North America. Crit Rev Microbiol. 2010;36(1):1-53. doi: 10.3109/10408410903241444. [PubMed: 20088682].

8. Kontoyiannis DP, Marr KA, Park BJ, Alexander BD, Anaissie EJ, Walsh TJ, et al. Prospective surveillance for invasive fungal infections in hematopoietic stem cell transplant recipients, 2001-2006: overview of the Transplant-Associated Infection Surveillance Network (TRANSNET) Database. Clin Infect Dis. 2010;50(8):1091-100. doi: 10.1086/651263. [PubMed: 20218877].

9. Dorschner P, McElroy LM, Ison MG. Nosocomial infections within the first month of solid organ transplantation. Transpl Infect Dis. 2014;16(2):171-87. doi: 10.1111/tid.12203. [PubMed: 24661423].

10. Santos L, Santos J, Rebelo A, da Silva M. Indoor air quality in community health centers: A preliminary study. Occup Saf Hyg. 2013:443-7. doi: 10.1201/b14391-91.

11. Liu G, Xiao M, Zhang X, Gal C, Chen X, Liu L, et al. A review of air filtration technologies for sustainable and healthy building ventilation. Sustain Cities Soc. 2017;32:375-96. doi:10.1016/j.scs.2017.04.011.

12. Moscato U, Borghini A, Teleman AA. HVAC management in health facilities. Indoor Air Quality in Healthcare Facilities. Springer; 2017. p. 95106. doi: 10.1007/978-3-319-49160-8_9.

13. Miriam K, Lonon I. Bioaerosol sampling (indoor air) Culturable organisms: bacteria, fungi, thermophilic actinomycetes. NIOSH Manual of Analytical Methods; 2003.
14. Marr KA, Carter RA, Crippa F, Wald A, Corey L. Epidemiology and outcome of mould infections in hematopoietic stem cell transplant recipients. Clin Infect Dis. 2002;34(7):909-17. doi:10.1086/339202. [PubMed: 11880955].

15. Zotti CM, Messori Ioli G, Charrier L, Arditi G, Argentero PA, Biglino A, et al. Hospital-acquired infections in Italy: a region wide prevalence study. J Hosp Infect. 2004;56(2):142-9. doi: 10.1016/j.jhin.2003.10.001. [PubMed: 15019227].

16. Cabo Verde S, Almeida SM, Matos J, Guerreiro D, Meneses M, Faria T, et al. Microbiological assessment of indoor air quality at different hospital sites. Res Microbiol. 2015;166(7):557-63. doi: 10.1016/j.resmic.2015.03.004. [PubMed: 25869221].

17. Awosika SA, Olajubu FA, Amusa NA. Microbiological assessment of indoor air of a teaching hospital in Nigeria. Asian Pac J Trop Biomed. 2012;2(6):465-8. doi: 10.1016/s2221-1691(12)60077-x.

18. Pappas PG, Alexander BD, Andes DR, Hadley S, Kauffman CA, Freifeld A, et al. Invasive fungal infections among organ transplant recipients: results of the Transplant-Associated Infection Surveillance Network (TRANSNET). Clin Infect Dis. 2010;50(8):1101-11. doi: 10.1086/651262. [PubMed: 20218876].

19. Abdul Salam ZH, Karlin RB, Ling ML, Yang KS. The impact of portable high-efficiency particulate air filters on the incidence of invasive aspergillosis in a large acute tertiary-care hospital. Am J Infect Control. 2010;38(4):e1-7. doi:10.1016/j.ajic.2009.09.014. [PubMed: 20129702].

20. Anaissie EJ, Stratton SL, Dignani MC, Lee CK, Summerbell RC, Rex $\mathrm{JH}$, et al. Pathogenic molds (including Aspergillus species) in hospital water distribution systems: a 3-year prospective study and clinical implications for patients with hematologic malignancies. Blood. 2003;101(7):2542-6. doi: 10.1182/blood-2002-02-0530. [PubMed: 12468437].

21. Araujo R, Cabral JP, Rodrigues AG. Air filtration systems and restrictive access conditions improve indoor air quality in clinical units: Penicillium as a general indicator of hospital indoor fungal levels. Am J Infect Control. 2008;36(2):129-34. doi: 10.1016/j.ajic.2007.02.001. [PubMed: 18313515].

22. Carreras E. Preventing exposure to moulds. Clin Microbiol Infect. 2006;12:77-83. doi:10.1111/j.1469-0691.2006.01608.x.

23. Clark RP, de Calcina-Goff ML. Some aspects of the airborne transmission of infection. J R Soc Interface. 2009;6 Suppl 6:S767-82. doi: 10.1098/rsif.2009.0236.focus. [PubMed: 19815574]. [PubMed Central: PMC2843950].

24. Chuaybamroong P, Choomseer P, Sribenjalux P. Comparison between hospital single air unit and central air unit for ventilation performances and airborne microbes. Aerosol Air Qual Res. 2008;8(1):2836. doi: 10.4209/aaqr.2007.04.0027.

25. Huang PY. Airborne and surface-bound microbial contamination in two intensive care units of a medical center in Central Taiwan.Aerosol Air Qual Res. 2013;13::1060-9. doi: 10.4209/aaqr.2012.08.0217.

26. Fumagalli S, Boncinelli L, Lo Nostro A, Valoti P, Baldereschi G, Di Bari $\mathrm{M}$, et al. Reduced cardiocirculatory complications with unrestrictive visiting policy in an intensive care unit: results from a pilot, randomized trial. Circulation. 2006;113(7):946-52. doi: 10.1161/CIRCULATIONAHA.105.572537. [PubMed:16490836].

27. Karthaus M, Buchheidt D. Invasive aspergillosis: new insights into disease, diagnostic and treatment. Curr Pharm Des. 2013;19(20):3569-94. doi: 10.2174/13816128113199990330. [PubMed: 23278538].

28. Ekhaise F, Ighosewe OU, Ajakpovi OD. Hospital indoor airborne microflora in private and government owned hospitals in Benin City, Nigeria. World J Med Sci. 2008;3(1):19-23.

29. Dehdashti A, Sahranavard N, Rostami R, Barkhordari A, Banayi Z. [Survey of bioaerosols type and concentration in the ambient air of hospitals in Damghan, Iran]. Occup med qJ. 2013;4(3):41-51. Persian.

30. Choobineh A, Rostam R, Tabatabae S. [Assessment of bioaerosols types and concentration in ambient air of Shiraz University of 
Medical Sciences educational hospitals, 2008]. Iran Occup Health. 2009;6(2):69-76. Persian.

31. Nourian A, Badali H. [A survey of spores of fungal agents in operatingroom equipments and special care units in Zanjan hospitals 2001].J Zanjan Univ Med Sci Health Serv. 2001;9(36):9-16. Persian.

32. Fernandez-Molina JV, Abad-Diaz-de-Cerio A, Sueiro-Olivares M, Pellon A, Ramirez-Garcia A, Garaizar J, et al. Rapid and specific detection of section Fumigati and Aspergillus fumigatus in human samples using a new multiplex real-time PCR. Diagn Microbiol Infect Dis. 2014;80(2):111-8. doi: 10.1016/j.diagmicrobio.2014.06.003. [PubMed:
25063549].

33. Zarrinfar H, Makimura K, Satoh K, Khodadadi H, Mirhendi H. Incidence of pulmonary aspergillosis and correlation of conventional diagnostic methods with nested PCR and real-time PCR assay using BAL fluid in intensive care unit patients. J Clin Lab Anal. 2013;27(3):181-5. doi: 10.1002/jcla.21580. [PubMed: 23686776].

34. Hoseinzadeh E, Taghavi M, Samarghandie MR. [Evaluation of fungal and bacterial aerosols in the different wards of Malayer city's hospitals in 2011-2012].J Hosp. 2014;13(3):99-108. Persian. 